\title{
Pengaruh Temperatur terhadap Pembuatan Papan Komposit Sekam Padi Berbasis Limbah HDPE menggunakan Metode Hot Press
}

\author{
Agung Fahmi Johari", Kardiman, Deri Teguh Santoso \\ Fakultas Teknik, Universitas Singaperbangsa Karawang \\ JL. H.S. Ronggowaluyo Teluk jambe Timur Telp. (0267) 641177 Ext. 305-Karawang 41361 \\ *Email: agungfahmijohari@gmail.com
}

Diterima: 09-11-2020; Direvisi: 26-03-2021; Dipublikasi: 27-04-2021

\begin{abstract}
Abstrak
Saat ini kebutuhan bahan papan terus mengalami peningkatan. Biasanya bahan papan ini merupakan bahan yang diperoleh dari kayu-kayu yang berasal dari hutan. Meningkatnya pemakaian kebutuhan akan papan ini dapat memberikan pengaruh yang kurang baik, yaitu hasil hutan terutama bahan kayu lama kelamaan akan semakin berkurang. Ketergantungan akan bahan kayu harus segera ditanggulangi, agar tidak mengurangi hasil hutan. Salah satu upaya yang dilakukan adalah dengan menggantikan kayu dengan material lain untuk memenuhi kebutuhan kayu pada bidang perumahan. Material lain yang digunakan ini tentunya harus mempunyai kualitas yang lebih unggul atau tidak kalah dengan produk kayu hutan tersebut. Penelitian ini bertujuan untuk menganalisis pengaruh temperatur terhadap pembuatan papan komposit sekam padi berbasis limbah HDPE menggunakan metode hot press. Uji fisis dilakukan dengan pengujian foto makro sedangkan uji mekanik dilakukan dengan pengujian tarik yang mengacu pada standar ASTM D 638-01. Hasil penelitian struktur makro papan komposit menunjukan bahwa pada temperatur $210^{\circ} \mathrm{C}$, papan komposit memiliki rongga lebih sedikit dibandingkan dengan temperatur dibawahnya, maka kenaikan temperatur berpengaruh terhadap kondisi struktur papan komposit. Nilai kekuatan tarik cenderung menurun dengan bertambahnya temperatur, kekuatan tarik tertinggi pada temperatur $170^{\circ} \mathrm{C}$ sebesar $11,630 \mathrm{MPa}$ dan terendah pada temperatur $185^{\circ} \mathrm{C}$ sebesar 8,835 MPa.
\end{abstract}

Kata kunci: Sekam Padi; HDPE; Sifat Fisis; Sifat Mekanik

\begin{abstract}
Currently, the need for board materials continues to increase. Usually this board material is a material obtained from wood that comes from the forest. The increasing use of the need for this board can have a less good influence, i.e. forest products, especially wood material over time will be reduced. The reliance on wood material must be addressed immediately, so as not to reduce forest yields. One of the efforts made is to replace wood with other materials to meet the needs of wood in the field of housing. Other materials used must have superior quality or not inferior to the forest wood products. This research aims to analyze the effect of temperature on the manufacture of HDPE waste-based rice husk composite boards using hot press methods. Fissile testing is done with macro photo testing while mechanical testing is conducted with tensile testing referring to ASTM D standard 638-01. The results of the composite board macro structure study showed that at $210^{\circ} \mathrm{C}$, the composite board has fewer cavities compared to the temperature below, so the increase in temperature affects the condition of the composite board structure. Tensile strength values tend to decrease with increased temperature, the highest tensile strength at $170^{\circ} \mathrm{C}$ at $11,630 \mathrm{MPa}$ and the lowest at $185^{\circ} \mathrm{C}$ at $8,835 \mathrm{MPa}$.
\end{abstract}

Keywords: Rice Husk; HDPE; Fission Properties; Mechanical Properties

\section{Pendahuluan}

Saat ini kebutuhan bahan papan terus mengalami peningkatan. Biasanya bahan papan ini merupakan bahan yang diperoleh dari kayu-kayu yang berasal dari hutan. Meningkatnya pemakaian kebutuhan akan papan ini dapat memberikan pengaruh yang kurang baik, yaitu hasil hutan terutama bahan kayu lama kelamaan akan semakin berkurang. Ketergantungan akan bahan kayu harus segera ditanggulangi, agar tidak mengurangi hasil hutan. Salah satu upaya yang dilakukan adalah dengan menggantikan kayu dengan material lain untuk memenuhi kebutuhan kayu pada bidang perumahan. Material lain yang digunakan ini tentunya harus mempunyai kualitas yang lebih unggul atau tidak kalah dengan produk kayu hutan tersebut [1]. 
Disisi lain limbah plastik adalah salah satu buangan atau sampah yang tidak dapat terurai oleh mikroorganisme pengurai (non biodegradable). Salah satu penyelesaian untuk mengatasi permasalahan tersebut sangat diperlukan usahausaha yang tujuannya untuk memanfaatkan limbah industri, baik yang berasal dari industri kayu maupun non kayu, sehingga dapat dipergunakan sebagai salah satu bahan baku pada industri pembuatan papan komposit [1]. Seperti yang diketahui padi merupakan salah satu produk utama pertanian yang ada di negara agraris seperti Indonesia, diketahui bahwa pada proses penggilingan padi sendiri menghasilkan $72 \%$ beras, 5\% dedak, dan 20-22\% adalah sekam [2].

Penggunaan sekam padi sebagai material komposit salah satunya untuk produk papan (panel). Papan partikel sendiri sebagai salah satu jenis komposit atau panel kayu yang terbuat dari partikel-pertikel yang diikat dengan bahan pengikat atau matriks kemudian di kempa secara Hot Press [3]. Wulandari telah melakukan penelitian sebelumnya pada pembuatan papan partikel sekam padi dan plastik jenis polietilena (PE) sebagai perekat mendapatkan hasil pengujian fisis telah memenuhi standar dari uji kerapatan atau massa jenis dengan nilai $660-710 \mathrm{~kg} / \mathrm{m}^{3}$ dan diklasifikasikan terhadap papan partikel medium (Medium Particle Board), nilai daya serap air dan pengembangan tebal telah sesuai dengan maksimal nilai pengembangan tebal $20 \%$. Hasil pengujian mekanik didapat nilai modulus of elasticity (MOE) dan modulus of rupture (MOR). Pada nilai MOE hasil yang didapat oleh papan partikel komposit semua sampel tidak memenuhi standar sedangkan untuk nilai MOR sudah memenuhi standar dengan nilai diatas minimal 7,845 MPa [4].

Perlakuan kimia tertentu perlu dilakukan terhadap serat alam untuk meningkatkan kompatibilitas serat alam sebagai penguat dalam komposit. Modifikasi kimia berpengaruh secara langsung terhadap struktur serat dan mengubah komposisi kimia serat, mengurangi kecenderungan penyerapan kelembaban oleh serat, sehingga akan memberikan ikatan antara serat dengan matriks yang lebih baik. Hal ini akan menghasilkan sifat mekanik dan termal komposit yang lebih baik. Kekuatan dan kekakuan dari serat tanaman terutama tergantung pada kandungan selulosanya, peningkatan kandungan selulosa adalah faktor kunci untuk meningkatkan sifat serat. Perlakuan alkali $(\mathrm{NaOH})$ dari serat alami adalah salah satu perlakuan kimia yang telah dikenal untuk meningkatkan kandungan selulosa melalui penghilangan hemiselulosa dan lignin [5]. Alkalisasi adalah salah satu cara modifikasi serat alam untuk meningkatkan kompatibilitas matriks-serat. [6].

Selain komposit berbahan kayu dalam penelitian lain membahas tentang komposit kayu plastik, yaitu komposit yang menggabungkan kayu dengan termoplastik seperti plastik polipropilena (PP), HDPE, dan lainya. Dari hasil perangkingan yang dilakukan oleh peneliti bahwa untuk tujuan mendapatkan nilai kekuatan fisis yang bagus digunakan komposisi 70:30 dengan temperatur $180^{\circ} \mathrm{C}$, nilai mekanik digunakan komposisi 50:50 dengan temperatur $170^{\circ} \mathrm{C}$ [7]. Penelitian tentang komposit limbah HDPE dengan serat alam telah dilakukan [8], pengaruh metode ekstrak serat agave dan limbah HDPE sebagai langit-langit atap menunjukkan bahwa serat dengan perlakuan panas sebelumnya akan meningkatkan kekuatannya dibanding dengan serat yang tidak mengalami perlakuan apapun sebelumnya [8]. Penelitian tentang perbedaan temperatur cetakan $150^{\circ} \mathrm{C}, 160^{\circ} \mathrm{C}, 170^{\circ} \mathrm{C}, 180^{\circ} \mathrm{C}$, dan $190^{\circ} \mathrm{C}$ dengan selama 15 menit, hasil penelitian menunjukkan nilai rata-rata keteguhan lentur yang paling tinggi adalah 4,357 $\mathrm{MPa}$ yaitu pada temperatur $190^{\circ} \mathrm{C}$ sedangkan nilai rata-rata keteguhan lentur yang paling rendah adalah $1,113 \mathrm{MPa}$ yaitu pada temperatur $160^{\circ} \mathrm{C}$. Hal ini membuktikan bahwa temperatur dies sangat berpengaruh terhadap kekuatan mekanik papan komposit yang dihasilkan [9].

Penelitian ini bertujuan untuk menganalisis pengaruh temperatur terhadap pembuatan papan komposit sekam padi berbasis limbah HDPE menggunakan metode hot press, temperatur yang diberikan pada saat proses hotpress adalah $170^{\circ} \mathrm{C}, 185^{\circ} \mathrm{C}, 200^{\circ} \mathrm{C}$, dan $210^{\circ} \mathrm{C}$. Uji fisis dilakukan dengan melakukan pengujian foto makro sedangkan uji mekanik dilakukan dengan melakukan pengujian tarik yang mengacu pada standar ASTM D 638-01. 
Agung Fahmi Johari dkk /Jurnal Rekayasa Mesin

p-ISSN: 1411-6863, e-ISSN: 2540-7678

Vol.16|No.1|17-24|April|2021

\section{Material dan Metodologi}

Sekam padi dan HDPE yang telah dicampur dengan fraksi volume 65\%:35\% kemudian dicetak menggunakan mesin hot press di Laboratorium Produksi Fakultas Teknik Universitas Singaperbangsa Karawang sedangkan pengujian tarik dilakukan di Laboratorium Bahan dan Material Politeknik Negeri Bandung. Alat hot press yang digunakan merupakan alat yang dirancang sebelumnya yang berfungsi untuk menyatukan matrik dan serat menjadi papan komposit, mesin hot press menggunakan system hidrolik yang dapat dilihat pada Gambar 1. Bahan yang digunakan pada penelitian ini adalah sekam padi, plastik HDPE, $\mathrm{NaOH}$, aquades, aluminium foil, gergaji besi, Gambar 2 (a) menunjukan limbah sekam padi dan Gambar 2 (b) menunjukan botol berbahan HDPE.

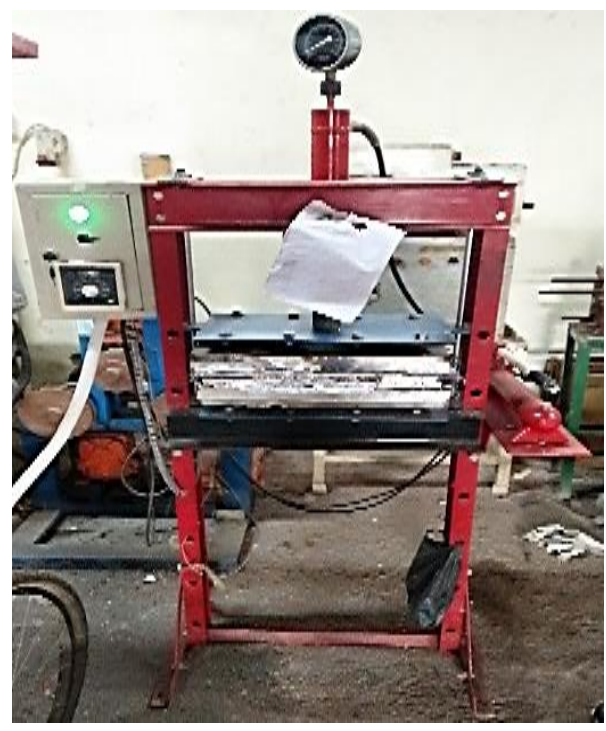

Gambar 1. Mesin hot press hidrolik

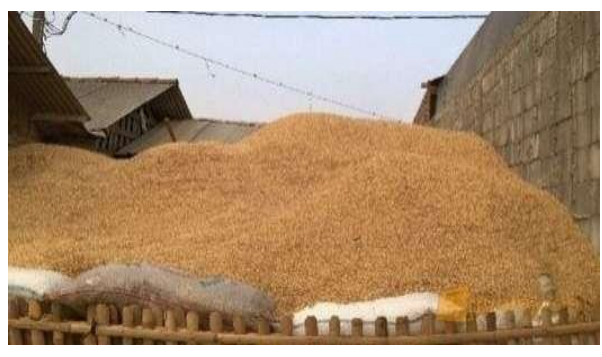

(a)

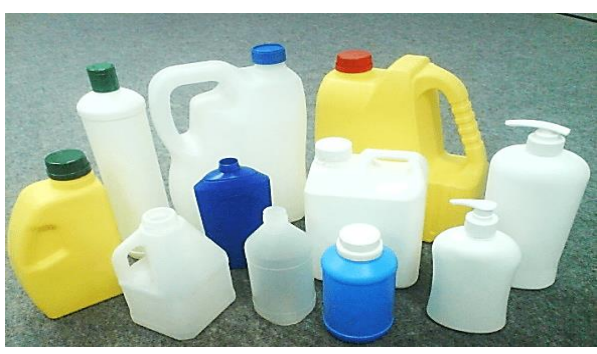

(b)

Gambar 2. (a) Limbah sekam padi [10] dan (b) Botol berbahan HDPE [3]

\subsection{Langkah-langkah pembuatan papan komposit}

Limbah sekam padi dialkalisasi menggunakan cairan $\mathrm{NaOH} 5 \%$ selama 2 jam kemudian dicuci dengan air yang mengalir lalu dikeringkan dibawah sinar matahari. Perlakuan alkali bertujuan untuk membuang lapisan lilin yang menyelimuti serat alam sebelum dijadikan material komposit [11]. Limbah plastik HDPE yang telah didapat kemudian dipotong dan diparut menggunakan parutan kelapa hal tersebut bertujuan untuk menghaluskan HDPE. Sekam padi dan HDPE yang telah dicampurkan lalu dituangkan kedalam cetakan dengan fraksi volume antara sekam padi dan HDPE yaitu 65\%:35\% kemudian dicetak menggunakan mesin hot press, temperatur yang diberikan pada saat proses hotpress yaitu $170^{\circ} \mathrm{C}, 185^{\circ} \mathrm{C}, 200^{\circ} \mathrm{C}$, dan $210^{\circ} \mathrm{C}$. Hasil cetakan papan komposit seperti yang ditunjukan pada Gambar 3 . 


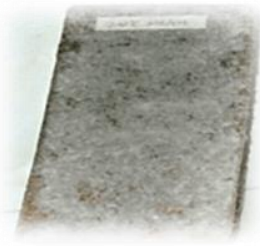

(a)

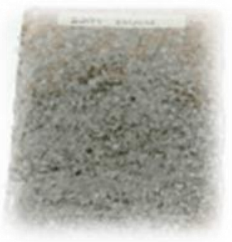

(b)

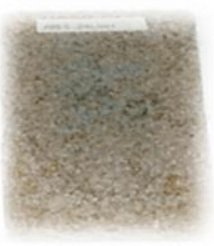

(c)

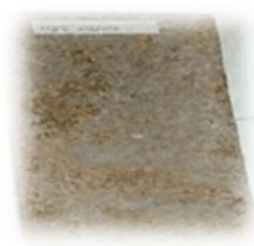

(d)

Gambar 3. Hasil cetakan papan komposit (a) $210^{\circ} \mathrm{C}$ (b) $200^{\circ} \mathrm{C}$ (c) $185^{\circ} \mathrm{C}$ (d) $170^{\circ} \mathrm{C}$

\subsection{Pengujian papan komposit}

Foto makro dilakukan pada spesimen papan komposit dari setiap variasi temperatur cetakan yang diberikan yaitu $170^{\circ} \mathrm{C}, 185^{\circ} \mathrm{C}, 200^{\circ} \mathrm{C}$, dan $210^{\circ} \mathrm{C}$. Bagian yang ditampilkan pada gambar foto makro merupakan bagian samping papan komposit yang telah dipotong menggunakan gergaji besi. Pengujian tarik merupakan pengujian yang bertujuan untuk mengetahui kekuatan suatu bahan berdasarkan ketahanan suatu material terhadap beban tarik dan keadaan dari suatu logam atau material lain [12]. Dimensi spesimen pengujian tarik mengacu pada standar ASTM D 638 0-1 Gambar 4. (a) merupakan spesimen uji tarik papan komposit dan Gambar 4. (b) merupakan mesin uji tarik.

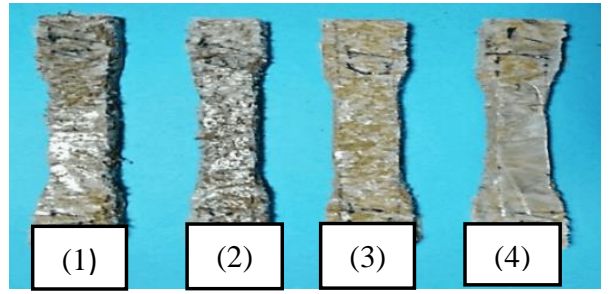

(a)

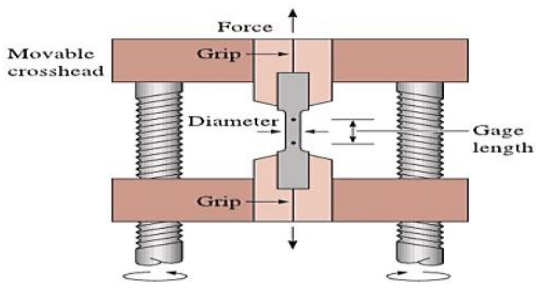

(b)

Gambar 4. (a) Spesimen uji tarik (1) $210^{\circ} \mathrm{C}$ (2) $200^{\circ} \mathrm{C}(3) 185^{\circ} \mathrm{C}(4) 170^{\circ} \mathrm{C}$ dan (b) Mesin uji tarik [13]

\section{Hasil dan Pembahasan}

\subsection{Foto Makro}

Dari Gambar 5 menunjukan hasil foto makro papan komposit temperatur $170^{\circ} \mathrm{C}$ fraksi volume sekam padi dan plastik HDPE 65\%:35\% bahwa pada warna serta bentuk dari sekam padi dan plastik HDPE tidak terjadi perubahan dikarenakan sekam padi memiliki ketahanan temperatur dibawah $200^{\circ} \mathrm{C}$, pada plastik HDPE memilik titik cair HDPE limbah $130^{\circ} \mathrm{C}$ [14] maka temperatur yang diberikan belum terlalu melampaui titik cairnya. Pada struktur foto makro spesimen papan komposit ditemukan banyak sekali rongga, hal ini disebabkan karena fraksi volume antara sekam padi dan plastik HDPE, partikel HDPE yang dominan akan mampu mengikat komposit secara optimal karena jumlah serat sedikit [3].

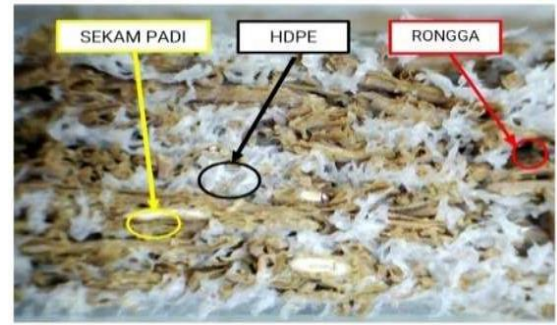

Gambar 5. Foto makro papan komposit temperatur $170^{\circ} \mathrm{C}$ 
Jumlah serat semakin sedikit menimbulkan potensi menurunnya kekuatan komposit, fenomena tersebut disebabkan semakin sedikit fraksi volume serat akan meningkatkan rongga atau pori-pori pada komposit [3]. Semakin meningkat jumlah rongga yang dihasilkan maka kekuatan komposit akan semakin menurun [3]. Faktor-faktor lain yang dapat mempengaruhi disetiap pengujian spesimen yaitu lamanya pemanasan mesin hot press yang kurang maksimal [9].

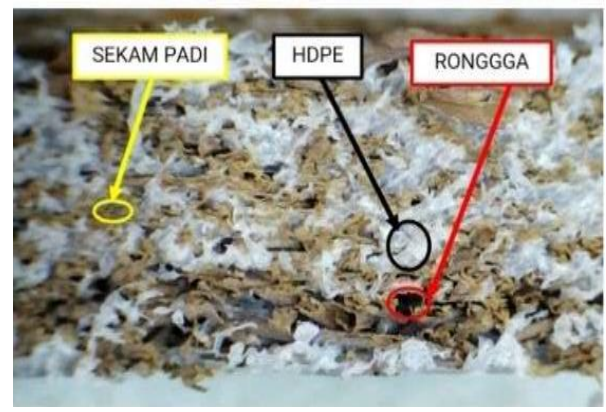

Gambar 6. Foto makro papan komposit temperatur $185^{\circ} \mathrm{C}$

Dari Gambar 6 menunjukan hasil foto makro papan komposit temperatur $185^{\circ} \mathrm{C}$ fraksi volume sekam padi dan plastik HDPE 65\%:35\% bahwa terjadi perubahan pada warna sekam, terlihat sekam lebih berwarna coklat dibandingkan dari temperatur $170^{\circ} \mathrm{C}$, namun sekam tidak mengalami kondisi gosong ini dikarenakan sekam yang tahan terhadap temperatur dibawa $200^{\circ} \mathrm{C}$ [9]. Pada plastik HDPE tidak terjadi perubahan warna maupun bentuk, HDPE memilik titik cair HDPE limbah $130^{\circ} \mathrm{C}$ [14]. Pada struktur papan komposit ditemukan rongga ini dikarenakan fraksi volume antara sekam dan HDPE. Jumlah serat semakin sedikit menimbulkan potensi menurunnya kekuatan komposit, fenomena tersebut disebabkan semakin sedikit fraksi volume serat akan meningkatkan rongga atau pori-pori pada komposit [3]. Semakin meningkat jumlah rongga yang dihasilkan maka kekuatan komposit akan semakin menurun [3]. Faktor-faktor lain yang dapat mempengaruhi disetiap pengujian spesimen yaitu lamanya pemanasan mesin hot press yang kurang maksimal [9].

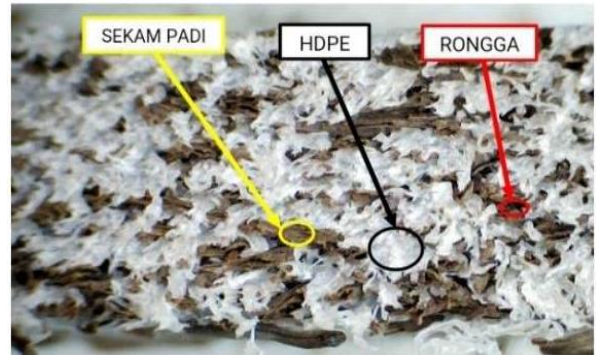

Gambar 7. Foto makro papan komposit temperatur $200^{\circ} \mathrm{C}$

Dari Gambar 7 menunjukan hasil foto makro papan komposit temperatur $200^{\circ} \mathrm{C}$ fraksi volume sekam padi dan plastik HDPE 65\%:35\% bahwa pada warna sekam terjadi perubahan warna dan sekam terlihat gosong ini karena sekam yang tahan terhadap temperatur dibawah $200^{\circ} \mathrm{C}$ [9]. Pada plastik HDPE terlihat bahwa terjadi peningkatan dominasi plastik HDPE terhadap sekam padi, plastik HDPE memilik titik cair HDPE limbah $130^{\circ} \mathrm{C}$ [14], terlihat bahwa semakin tinggi temperatur yang diberikan HDPE semakin meleleh dan semakin mendominasi. Pada struktur papan komposit ditemukan rongga ini dikarenakan fraksi volume antara sekam dan HDPE. Jumlah serat semakin sedikit menimbulkan potensi menurunnya kekuatan komposit, fenomena tersebut disebabkan semakin sedikit fraksi volume serat akan 
meningkatkan rongga atau pori-pori pada komposit [3]. Semakin meningkat jumlah rongga yang dihasilkan maka kekuatan komposit akan semakin menurun [3].

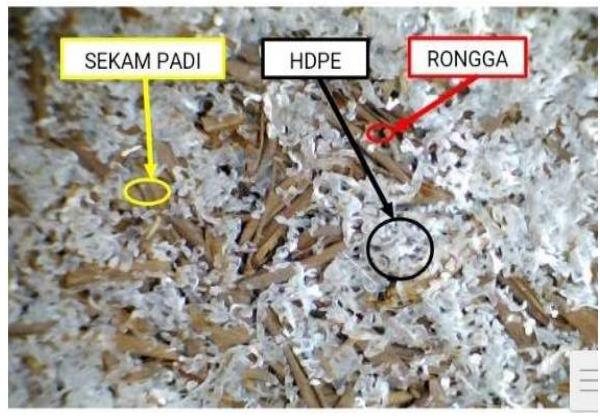

Gambar 8. Foto makro papan komposit temperatur $210^{\circ} \mathrm{C}$

Dari Gambar 8 menunjukan hasil foto makro papan komposit temperatur $210^{\circ} \mathrm{C}$ fraksi volume sekam padi dan plastik HDPE 65\%:35\% bahwa pada kondisi warna sekam telah terjadi perubahan warna dari warna yang semula, sekam terlihat berwarna coklat ini karena sekam yang tahan dibawah suhu $200^{\circ} \mathrm{C}$ [9], pada kondisi HDPE terlihat HDPE mendominasi struktur papan komposit, HDPE limbah memilik titik cair $130^{\circ} \mathrm{C}$ [9] pada pemberian temperaturnya sudah melampaui titik cair. Namun terlihat dari struturnya, pada pemberian temperatur hot press $210^{\circ} \mathrm{C}$ rongga terlihat berkurang dibandingkan dengan pemberian temperatur dibawahnya. Faktor-faktor lain yang dapat mempengaruhi disetiap pengujian spesimen yaitu lamanya pemanasan mesin hot press yang kurang maksimal [9].

\subsection{Pengujian tarik}

Pengujian kekuatan tarik dilakukan dengan tujuan untuk mengetahui sifat-sifat mekanik suatu material seperti kekuatan tarik, tegangan luluh dan regangan yang terjadi [15]. Pada penelitian ini, pengujian tarik dilakukan untuk mengetahui seberapa besar pengaruh temperatur cetakan terhadap kekuatan tarik spesimen.

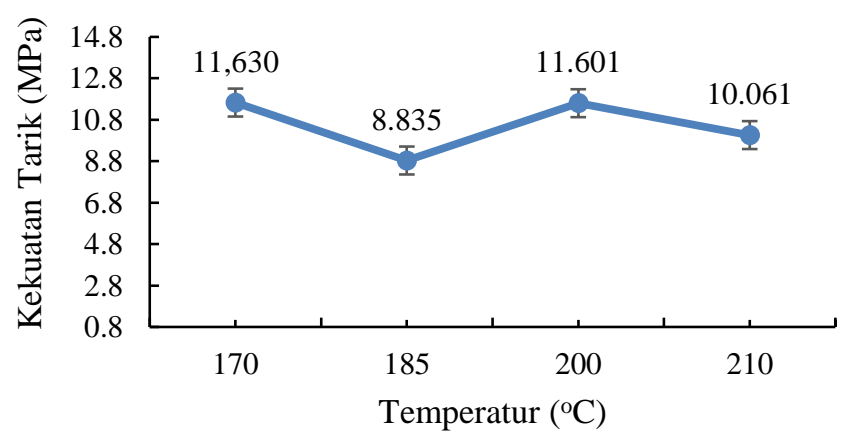

Gambar 9. Hubungan kekuatan tarik terhadap temperatur cetakan

Dari Gambar 9 diperoleh hasil kekuatan tarik papan komposit, kekuatan tarik tertinggi didapat dari temperatur $170^{\circ} \mathrm{C}$ yaitu sebesar 11,630 MPa, kekuatan tarik terendah yaitu pada temperatur $185^{\circ} \mathrm{C}$ sebesar $8,835 \mathrm{MPa}$, pada temperatur $200^{\circ} \mathrm{C}$ memiliki nilai kekuatan tarik sebesar $11,601 \mathrm{MPa}$ dan pada temperatur $210^{\circ} \mathrm{C}$ memiliki kekuatan tarik sebesar 10,061 MPa. Dari hasil kekuatan tarik menunjukan bahwa temperatur cetakan yang diberikan berpengaruh terhadap nilai kekuatan tarik papan komposit, kekuatan tarik cenderung menurun dengan peningkatan temperatur cetakan, perlakuan siklus termal mengakibatkan turunnya kekuatan tarik, karena semakin tinggi temperatur yang diberikan berpengaruh 
terhadap sifat HDPE [8], hal ini juga menujukan bahwa heater atau pemanas yang tidak merata akan membuat kekuatan tarik menjadi tidak optimal. Komposisi matriks yang rendah menyebabkan rendahnya kekompakan dan interaksi antar muka campuran [1], hal tersebut menunjukan bahwa komposisi matriks yang diberikan berpengaruh terhadap kekuatan tarik, yang mana pada penelitian ini HDPE berfungsi sebagai matriksnya. Pada temperatur $185^{\circ} \mathrm{C}$ terjadi penurunan yang signifikan pada nilai kekuatan tarik, dari segi analisis kondisi tersebut dapat terjadi karena matriks yang tidak merata saat proses pencampuran sekam padi dan HDPE, sehingga membuat kekosongan matriks pada serat sekam, namun dari segi teoritis penurunan nilai kekuatan tarik yang terlalu signifikan tidak harus terjadi karena fraksi volume dan kekuatan pengepresan dari setiap spesimen uji mempunyai nilai yang sama. Penelitian yang telah dilakukan yaitu uji mekanik berupa uji tarik terhadap komposit limbah HDPE serat cantula memiliki hasil kekuatan tarik yang cenderung menurut seiring dengan bertambahnya temperatur siklus, hasil tertinggi pada temperatur siklus $60^{\circ} \mathrm{C}$ sebesar $25 \mathrm{MPa}$, diikuti dengan temperatur siklus $70^{\circ} \mathrm{C}$ sebesar $20 \mathrm{MPa}, 80^{\circ} \mathrm{C}$ sebesar $19 \mathrm{MPa}, 90^{\circ} \mathrm{C}$ sebesar $18 \mathrm{MPa}$, dan $100^{\circ} \mathrm{C}$ sebesar $17 \mathrm{MPa}$ [8].

\section{Kesimpulan}

Kesimpulan dari penelitian ini adalah pada analisis struktur makro kondisi sekam padi dan HDPE pada setiap temperatur cetakan sangatlah berbeda-beda, namun terlihat bahwa semakin tinggi temperatur yang diberikan rongga pada permukaan papan komposit semakin berkurang, hal ini disebabkan karena HDPE yang dipanaskan pada proses hot pres semakin mecair dalam kondisi temperatur tinggi. Pada pengujian tarik didapatkan hasil bahwa kekuatan tarik papan komposit cenderung menurun dengan bertambahnya temperatur, nilai kekuatan tarik terendah pada temperatur $185^{\circ} \mathrm{C}$ sebesar 8,835 MPa.

\section{Daftar Pustaka}

[1] Fathanah, U., "Kualitas Papan Komposit dari Sekam Padi dan Plastik HDPE Daur Ulang Menggunakan Maleic Anhydride (MAH) sebagai Compatibilizer," Jurnal Rekayasa Kimia dan Lingkungan, vol. VIII, no. 2, pp. 53-59, 2011.

[2] Fauziah, D. Wahyuni and B. P. Lapanporo, "Analisis Sifat Fisik dan Mekanik Papan Partikel Berbahan Dasar Sekam Padi," POSITRON, vol. IV, no. 2, pp. 60-63, 2014.

[3] Nurhidayat, A., "Pengaruh Fraksi Volume Pada Pembuatan Komposit HDPE Limbah-Cantula dan Berbagai Jenis Perekat Dalam Pembuatan Laminate," Tesis Magister Program Studi Teknik Mesi, Universitas Sebelas Maret Surakarta, 2013.

[4] Wulandari, "Pembuatan dan Pengujian Papan Partikel Komposit Berbahan Baku Sekam Padi Dengan Menggunakan Proses Hot Press," Tugas Akhir Program Studi Teknik Mesin, Universitas Singaperbangsa Karawang, 2018.

[5] Witono, K., Irawan, Y.S., Soenoko, R., Heru, S., "Pengaruh Perlakuan Alkali (NaOH) Terhadap Morfologi dan Kekuatan Tarik Serat Mendong," Jurnal Rekayasa Mesin, vol. IV, no. 3, pp. 227-234, 2013.

[6] Maryanti, B., Sonief, A.A., Wahyudi, S., "Pengaruh Alkalisasi Komposit Serat Kelapa-Poliester Terhadap Kekuatan Tarik," Jurnal Rekayasa Mesin, vol. II, no. 2, pp. 123-129, 2011.

[7] Sarumaha, P.S.B., "Kualitas Komposit Kayu Plastik dari Limbah Serat Buah Sawit dan Polipropilena Daur Ulang," Skripsi Teknologi Hasil Hutan, Universitas Sumatera Utara, 2008. 
[8] Wiyono, T., Ibnu Mubtadi, B., "Pengaruh Siklus Panas pada Komposit Limbah Plastik HDPE-Serat Cantula sebagai Bahan Material Alternatif Melalui Uji Mekanik," POLITEKNOSAINS, vol. XV, no. 2, pp. 22-29, 16.

[9] Kardiman, F.D., Fuadi, F.C., Widianto, E., "Pengaruh Temperatur Terhadap Sifat Mekanik Pada Pembuatan Papan Komposit Berbasis Sekam Padi dan Matriks HDPE," Jurnal Ilmiah Teknik Mesin, vol. XI, no. 1, pp. 10-18, 2019.

[10] Putri, W.D., "Mahasiswa Unej Ciptakan Beton dari Abu Sekam Padi dan Ampas Tebu," Republika.co.id, 08 April 2016. [Online]. Available: https://www.republika.co.id. [Accessed 20 Mei 2020].

[11] Susilowati, S.E., "Studi Perlakuan Alkali Terhadap Sifat Mekanik Bahan Komposit Berpenguat Sekam Padi," Jurnal Kajian Teknik Mesin, vol. II, no. 1, pp. 67-80, 2017.

[12] Wahyudyanto, J., "Pengaruh Filler Mikro Partikel Karbon Tempurung Kelapa (CMP-CS) Terhadap Photo Makro dan Kekuatan Tarik Komposit Polyester," Publikasi Ilmiah Program Studi Teknik Mesin, Universitas Muhammadiyah Surakarta, 2016.

[13] Wijoyo, J., "Sifat Fisika Papan Semen Partikel Limbah Serbuk Gergaji Kayu Jati (Tectona Grandis)," Skripsi Program studi kehutanan,Universitas Mataram, 2017.

[14] Hartanto, L., "Study Perlakuan Alkali dan Fraksi Volume Serat Terhadap Kekuatan Bending, Tarik, dan Impak Komposit Berpenguat Serat Rami Bermatrik Polyester BQTN 157," Tugas Akhir Program Studi Teknik Mesin, Universitas Muhammadiyah Surakarta, 2009.

[15] Hasibuan, M., "Pengaruh Ketinggian Batang dan Jumlah Lapisan Terhadap Sifat Fisis dan Sifat Mekanis Papan Laminasi dari Batang Kelapa Sawit (Elaeisguineensis Jacq) Dengan Perekat Polyvinylacetate (PVAc)," Skripsi Departemen Teknologi Hasil Hutan, Universitas Sumatera Utara, 2017. 